\title{
Effective Methods for Structural Health Monitoring of Critical Zones of Scalable Wind Turbine Blades
}

\author{
Adriana Savin ${ }^{1, *}$ - Nicoleta Iftimie ${ }^{1}$ - Rozina Steigmann ${ }^{1}$ - Dorin Rosu ${ }^{2}-$ \\ Gabriel Silviu Dobrescu 1 - Janez Grum ${ }^{3}$ - Paul Doru Barsanescu ${ }^{4}$ \\ ${ }^{1}$ National Institute of R\&D for Technical Physics, Nondestructive Testing Department, Romania \\ ${ }^{2}$ S.C. Compozite S.A., Romania \\ ${ }^{3}$ University of Ljubljana, Faculty of Mechanical Engineering, Slovenia \\ ${ }^{4}$ Gheorghe Asachi Technical University, Faculty of Mechanical Engineering, Romania
}

\begin{abstract}
The most important part of wind turbine is the blade that must be tested during fabrication and functioning when can be damaged by moisture absorption, fatigue, wind gusts or lightning strikes. The common defects in turbine blades may be faulty microscopic and mesoscopic appeared in matrix, broken fibers can also appear and develop under moderated loads, or cracks and delaminations due to low energy impacts, etc. The paper presents the results obtained from testing and monitoring of a scalable wind turbine blade (WTB) using different sensors placed on critical location, which were determined by finite element method (FEM) simulation. A comparison between the complementary methods is carried out in order to choose the most efficient method as quality/price ratio.

Keywords: wind turbine blades, structural health monitoring (SHM), nondestructive testing, wireless sensors, fiber Bragg gratings (FBG), strain gauges (SG)

\footnotetext{
Highlights

- The monitoring of scalable wind turbine blade has been carried out using complementary nondestructive evaluation methods.

- $\quad$ Different types of sensors have been employed as optical fiber sensors, fiber Bragg grating type, wireless sensors based on metamaterials and classical strain gauges rosette placed on critical zones of the blade.

- The critical zones have been determined using finite element method.

- $\quad$ The results have been compared in order experimental emphasize the maximum concentration stress zones, theoretically determined.
}

\section{INTRODUCTION}

The problem of climate changing, due to pollution includes not only modification of average temperatures but also changing of its different aspects as winds, quantity and precipitation categories and frequency of extreme meteorological events. Power plants in the European Union will have to cut the amount of toxic pollutants they emit such as sulfur dioxide and mercury, nitrogen oxides, arsenic, lead and cadmium emissions under new rules approved by EU member states on 2017 and widely applauded by environmental groups. Thus, the market for electrical energy obtained by harvesting wind power is expanding [1].

In Romania over $3 \%$ from annual electricity is produced by wind turbines, the majority being GE1.5sle or similar, having the length of the blade of $33.5 \mathrm{~m}$ and the height of tower of $65 / 80 \mathrm{~m} \mathrm{[2]}$. In January 1st, 2017, Romania recorded 3025 MW installed in wind turbines (WT), the total number of installed turbines being 1250 at an average turbine power of $2.5 \mathrm{MW}$ (located in 80 wind farms in operation, the average of a wind farm in Romania being $40 \mathrm{MW}$ ) [3]. WT development and increasing of their capacity are important ways to respond to growing global energy demand.

Most of the past years papers are focused on optimizing WT from the point of view of gearbox analysis [4] design parameters to minimize energy costs, maximize energy production [5] and minimize wind turbine blade (WTB) sizes [6] to [8]. This type of optimization resulted in slender blades, with less resistance. All these had implications over the blade profile and lead to rethinking of weight and stability of the blade. Yang et al. [9] studied major design cases meanwhile others [10] were focused on cases with loadings in the design of blades using laser triangulation in order to reduce the design time [11] and the evaluation of their deformations.

In the process of optimizing the structural design of the blade, the priority is to prevent failure in compliance with structural resistance requirements. Critical areas were taken into account when optimizing the blade [12] selecting the Tsai-Wu failure criterion. It can be concluded that the decision to maximize the aerodynamic performances to optimize the objective functions of the wind turbine has to be done 
according to safety in operation rules, with the aim of minimum report cost of energy by maximum annual energy production. Chehouri et al. [13] highlights the need to further study the issues that have not been resolved satisfactorily: complete load calculation and composite structural optimization.

We analyzed the methods of calculating blade loads: the basic method was to translate the aerodynamic load into a concentrated force for numerical simulation using moment's theory. Since it is impossible of revealing the pressure distribution of the blade surface, is preferable to be chosen the substitution of the inverse design tool with computational fluid dynamics software and to load the distribution into a finite element method (FEM) solver to investigate the mechanical strength [14]. That needs increasing of the computational time of the optimization process. The use of glass fiber-reinforced plastics (GFRP) is popular in making blades because of it offers production of parts with low weight, high stiffness and good load resistance. However, the use of traditional two dimensional (2D) laminates due to their low properties (stiffness, low fatigue strength) interlaminar failure at shear followed by fracture impose behavioral analysis by complementary methods.

In order to undertake the design optimization, analysis of loads in the design of blades and deformation evaluation, a scalable WTB has been constructed. It had the scaled dynamics of a full-scale blade as well as enough sensors for measurements and monitoring. The scaled WTB studies have been developed to test WTB with better accuracy and lower cost, but with results relevant to full scale WTB [15].

In order to obtain greater efficiency and to increase the generated power, the general trend is to use large-diameter rotors and manufacturing the blades with GFRP due to their low weight. This resulted in WT blades length of $60 \mathrm{~m}$ [16]. The blades are usually subject to random and complex mechanical stresses. The most common defects in turbine blades may be faulty microscopic and mesoscopic appeared in matrix, no detected by classical nondestructive testing (i.e. using phased array sensors). Broken fibers can also appear and develop under moderated loads, or cracks and delaminations due to low energy impacts, etc. However, large blades led to no concrete data in due time during in-service inspection. These explain the attention given to structural health monitoring (SHM) [17] systems for WTB, development and consolidation of diagnosis, prognosis methodologies, damage detection (location and their nature). The SHM process involves the observation of a system over time using periodically sampled dynamic response measurements from an arrangement of sensors, the extraction of damage-sensitive features from these measurements to determine the current state of system health [18]. Fig. 1 illustrates the SHM system concept [10], the blades damages shall be detected and evaluated with high probability of detection and reliability coefficient.

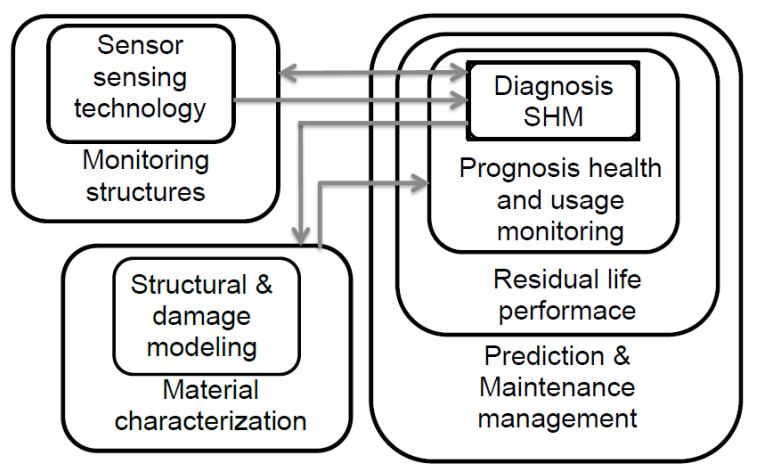

Fig. 1. SHM system

For an estimated lifetime of 20 years and extended as long as is possible, the long-term integrity of a blade became a very interested area. The monitoring of WTB made from GFRP have been reviewed in [9], proposing either statistical pattern recognition using simulation or experimental data, or in [19] considering mechanical property testing and full-scale testing as well as nondestructive testing methods. In order to calculate the lifetime of GFRP structures used in WTB construction, it is essential to have access to information about fatigue resistance of the material. These data include a number of fatigue tests in the frame of specific combinations of amplitude and average stress.

From extended fatigue points of view of GFRP in WTB [20] and, [21] different databases are compiled but the data are not compatible with other experiments databases, being hard to employ them into new ones. There are many literature reviews concerning WTB starting from design, propulsion and including theories of maximum efficiency [21] to [25]. In order to decrease the fabrication and maintenance costs, as well as for avoiding unproductive time, the nondestructive testing (NDT) is required both during fabrication and in-service. NDT techniques for inservice inspection and determination of regions with high degradation risks are developed (function on the type and the size of the WT) [26].

The results of complex mechanical tests, performed on scalable WTB model (in our case a 
blade of $1750 \mathrm{~mm}$ length) are used to give efficiency to monitoring strategy. Using FEM, the maximum stress zones [27] and damage evolution and remnant stress [28] have been determined.

The paper presents results of testing of a WTB, under static loading, using three types of sensors (i.e. radio-frequency identification (RFID) strain wireless sensor (WRS), optical fiber (OF) fiber Bragg gratings (FBG), stress/strain gauges (SG)) in order to detect possible damages that further can lead to risky flaws. The objective of the current work is to demonstrate that the methodologies for scaled blades can be applied to real size WTB. To the best of our knowledge, this investigation has not been performed for WTBs before.

\section{PRINCIPLES}

WTBs are most exposed component of WT so that their structures are designed and realized based on the concept that a layered structure more easily supports an early stage damage that can be stopped when it has a tendency to propagate following the repeated loads prescribed by the project. Based on $a$ priori knowledge about WTBs, the sensors used for their characterization are placed on the most expected damage area, aiming the minimizing of the sensors number.

\subsection{Sensors with Fiber Bragg Grating}

SHM includes the use of FBG for detecting delamination in composite laminates [29] and monitor impact event occurrence [30] and [31]. A FBG is a periodic or semiperiodic permanent perturbation of the fiber core refractive index. Optical fiber (OF) sensors are made based on OF in integrated structures. This sensor can monitor the structure in critical regions. The central wavelength of this signal, called Bragg wavelength $\lambda_{B}$ is related to the physical parameters of the grating according to $\lambda_{B}=2 n \Lambda$ where $n$ is the effective refractive index of the fundamental mode propagating inside the fiber; $\Lambda$ is the spacing between gratings, known as grating period. When the $\mathrm{OF}$ is submitted to strain, the central wavelength is displaced to higher or smaller values [32].

The direction and the magnitude of displacement are proportional with the modification of strain or temperature. The strain axial sensitivity is $d \lambda_{B} / d \varepsilon \approx \lambda_{B}\left(1-p_{e}\right)$ where $\partial \lambda_{B}$ is the OF wavelength shift; $\varepsilon<<1, p_{e}$ is photo-elastic coefficient of the fiber $p_{e} \approx 0.22$. OF sensors, whose gauge lengths are about $10 \mathrm{~mm}$ were used for SHM. At the wavelength of our OF, $\partial \lambda_{B} / \lambda_{B} \approx 0.78 \varepsilon$ so the OF strain sensing can be expressed as $\varepsilon=\frac{1}{0.78 \times 10^{-6}} \frac{\Delta \lambda_{B}}{\lambda_{B}}$. In structure of WTB, three OF sensors were embedded along the central longitude of the blade, placed into critical points determined by FEM of blade under bending (red region in Fig. 7).

The optical block diagram of measurement is shown in Fig. 3. The reflectance cell consists of a double FBGs housed in an athermal package and reflect two wavelength peaks (around $1529 \mathrm{~nm}$ and $1571 \mathrm{~nm}$ ). The measurement system consists of a broadband light source, light-emitting diode (LED) that illuminates the optical input line and a reference cell after passing through a $2 \times 2$ double-clad fiber couplers that combine the double-clad fiber (single mode core surrounded by a multimode inner cladding) with a standard step-index multimode fiber.
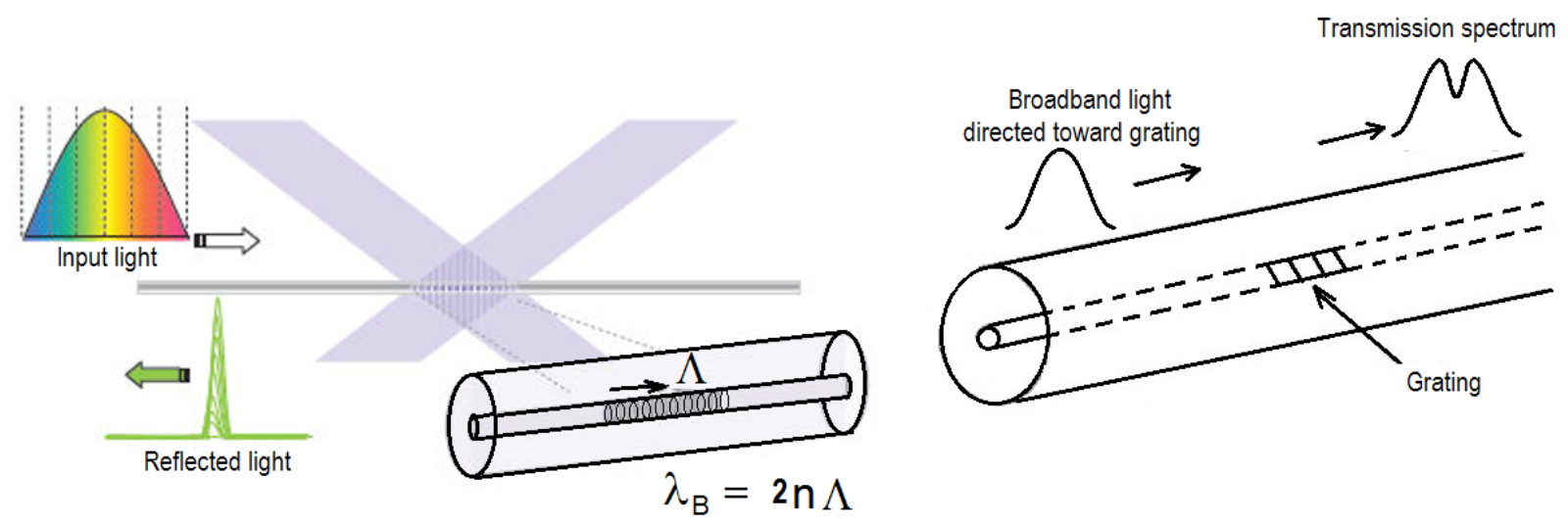

Fig. 2. Fiber Bragg gratings principle [26] 

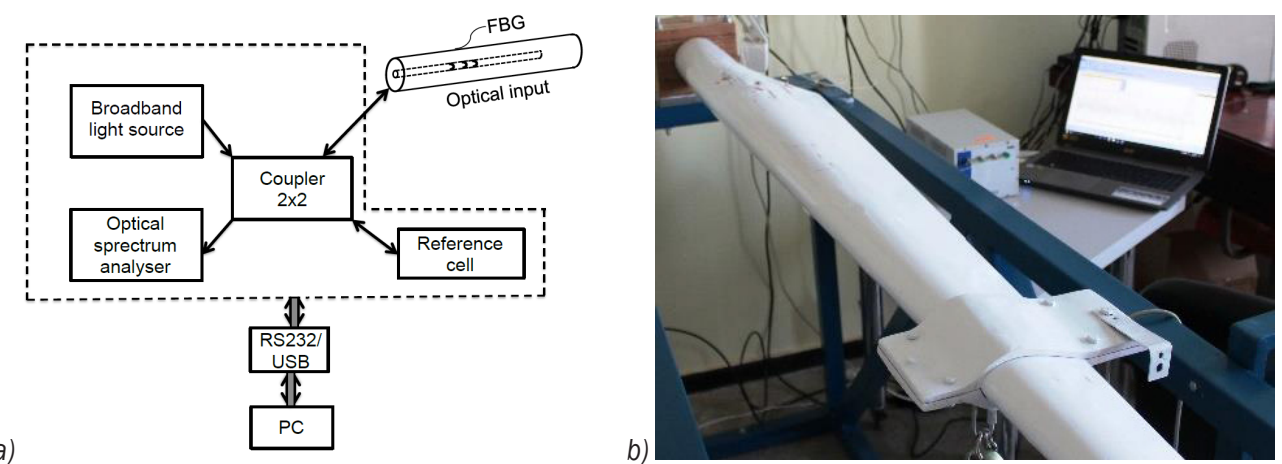

Fig. 3. Basic diagram and FBG interrogator; a) optical block diagram of measurement, b) measurement system

\subsection{Wireless Sensors}

The passive WRS designed to monitor stress/strain status have as sensitive element that follows the relative displacement (compression or tension) of its components due to loads. In specific construction as $2 \mathrm{D}$ geometry on flexible dielectric support with thickness $t$, having $\varepsilon_{d}$ permittivity and $\sigma_{d}$ conductivity, copper split-ring resonator (SRR) can be used as stress/strain sensors [33] and [34]. The sensor consists of a folded rectangular microstrip patch antenna [35] coupled with a tunable inductive SRR, with central space of SRR filled with a material having electrical conductivity $\sigma_{g}$, length $g$ and width $l$, it forms the terminals of a new capacitor $C_{m}$, representing the strain cell and with a passive integrated circuit (IC) chip. When over the capacitive strain cell, $\eta$ strain is applied, the capacitance is modified.

The structure of this type of sensor is shown in Fig. $4 \mathrm{a}$, the sensing element is shown in Fig. $4 \mathrm{~b}$.

Resonance frequency of sensor is in range of radio frequency $(\mathrm{RF})$ and microwaves, depends of geometrical dimensions and design. WRS presents resonant properties [36] and the inductance and the capacitance are given by [37]. The resonance frequency is $f_{r}=c /\left[4(L+\Delta L) \sqrt{\varepsilon_{r}}\right]$ with $c$ speed of light in vacuum, $L$ the length of the copper layer, $\varepsilon_{r}$ the dielectric permittivity of the substrate, $\Delta L$ is the additional length who compensate the effect due to thickness, width and dielectric constant of the substrate.

Parallel with capacitance $C$, a capacitive element sensitive to stress/strain is connected, with the capacitance varying linear with the strain as $C_{\text {sensitive }}=\varepsilon_{r} \varepsilon_{0} l g /[t(1+\eta)]$ with $t$ thickness of dielectric layer and $\eta$ strain in $[\mu \mathrm{m} / \mathrm{m}]$. For the capacitive element, sensitive to stress/strain, to function upon a law closer to this, it is imposed that the Poisson ratio of dielectric support shall be as high as possible. For polyimide, the layer supporting copper strips, the Poisson ratio is 0.4 . If $\eta=10 \mu \mathrm{m} / \mathrm{m}$, the connection between the two-capacitance make $C$ increases with $10 \%$, inductance $L$ remaining unchanged. Detection system consist in a RFID reader and a RFID tag [38], the tag including the sensor and the IC. When the sensor detect a modification of the strain $\eta$, the shifted resonance frequency becomes

$$
f_{r}^{\prime}=\frac{c}{4(1+\eta)(L+\Delta L) \sqrt{\varepsilon_{r}}}=\frac{f_{r}}{1+\eta} \approx f_{r}(1-\eta) .
$$

For a small load, the resonance frequency modifies almost linear with load, the load can be a)

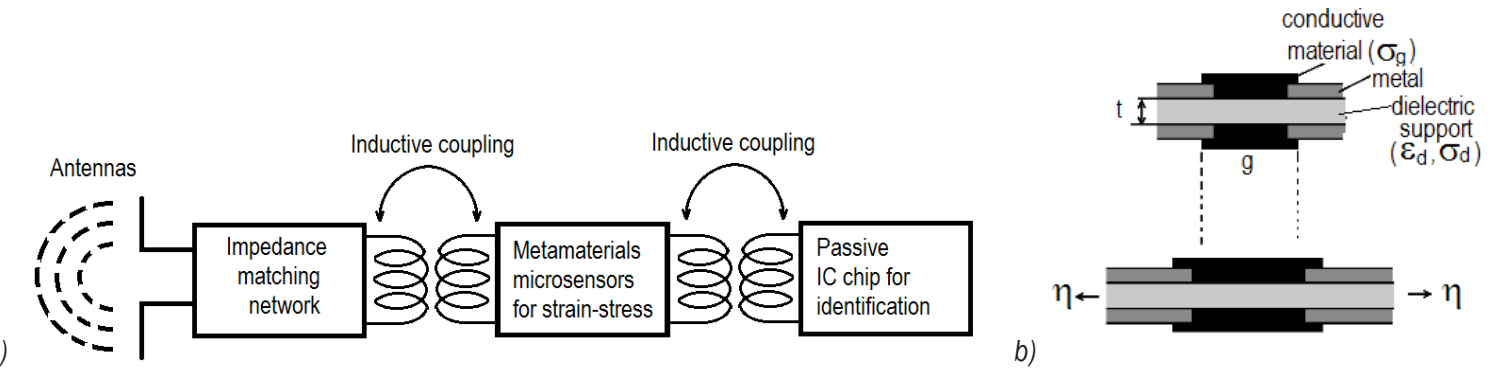

Fig. 4. Metamaterial passive wireless sensors for SHM: a) schematic of a RF / microwave - RFID tag; b) schematic of sensing element 
determined if the resonance frequency is measured. Applying a loading force, the inside dielectric is deformed leading to shorting height and increasing of contact area between dielectric and sensing area. Thus, the capacitance is increased transducing the modification of resonant frequency by integrated inductor-capacitor (LC) circuit [27]. The capacitive responses and the applied loads follow a linear relationship, the measuring device providing direct plots of microstrain vs. force.

The RFID tag antenna assures that the interrogation frequency $f$ shall be equal with the one of RFID tag to obtain perfect matching of impedance between antenna tag and IC chip. The smallest amount of energy must be transmitted toward reader to activate RFID tag, the transmitted power threshold (measured through the reader) reach minimum value at resonance frequency.

\subsection{Strain Gauges}

Three-element strain gage rosette must be employed to determine the principal strains in a general biaxial stress state when the directions of the principal axes are unknown. The usual goal of experimental stress analysis, however, is to arrive at the principal stresses, for comparison with some criterion of failure [38]. Three-element strain gage rosette have the advantages of being thin and flexible, with greater conformability to curved surfaces, minimal reinforcing effect, superior heat dissipation to the test part. They are available in all standard forms of gage construction, and generally accepts all standard optional features, optimal stability, and maximum freedom in lead wire routing and bonding.

The equations for calculating principal strains from three rosette strain measurements are derived from what is known as a "strain-transformation" relationship. For each gauge, maximum and minimum specific strains $\varepsilon_{\max }, \varepsilon_{\min }$, the arbitrary angle $\theta$ from the major principal axis, maximum shear strain $\gamma_{\max }$, maximum and minimum normal stress, $\sigma_{\max }, \sigma_{\min .}$ are calculated.

\section{EXPERIMENTAL SET-UP}

Detecting early-stage WTB degradations and monitoring their progress over time can lead to improved diagnostic capability and the development of more efficient repair strategies and, last but not least, the improvement of structural blade design. Taking into account the efficacy of the method and a priori knowledge about WTB (obtained by simulations), the sensors is distributed on the most expected damage area, aiming the minimizing of the sensors number (Figs. 5 and 6). The blade has been realized from E-glass/epoxy EPIKOTE Resin MGS LR 385 composite. The leading edge is straight and the trailing edge conical for an easy construction. The profile follows NACA airfoil [15].

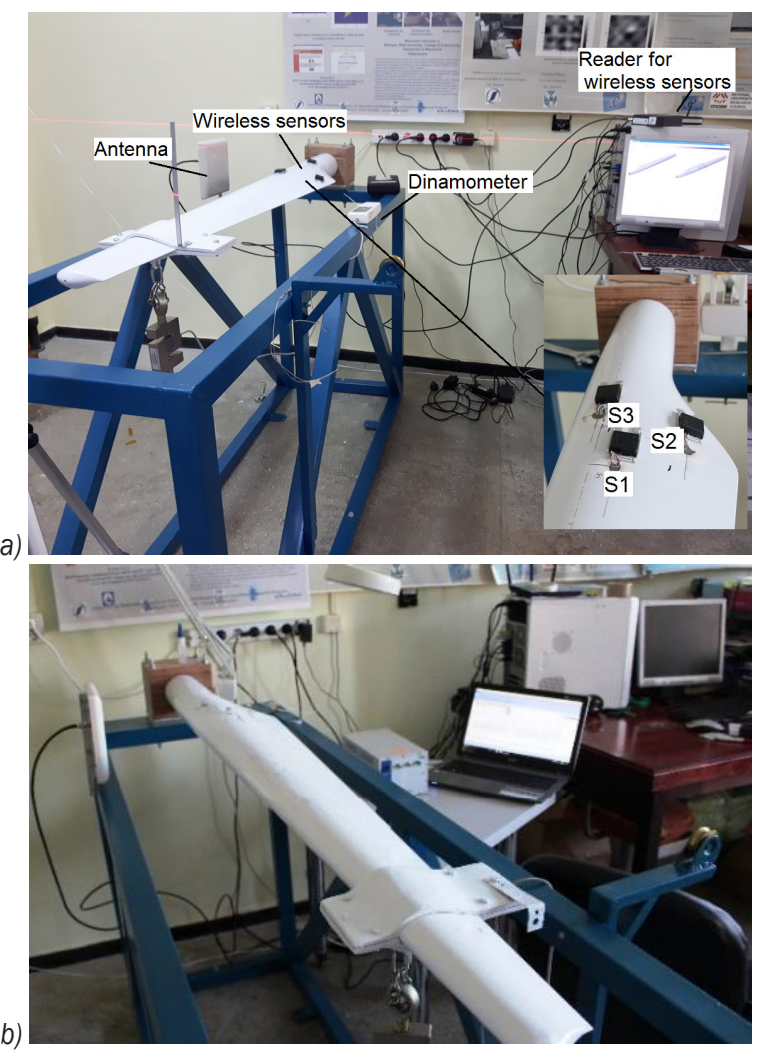

Fig. 5. Testing stand for a) wireless sensors and b) optical fiber measurements

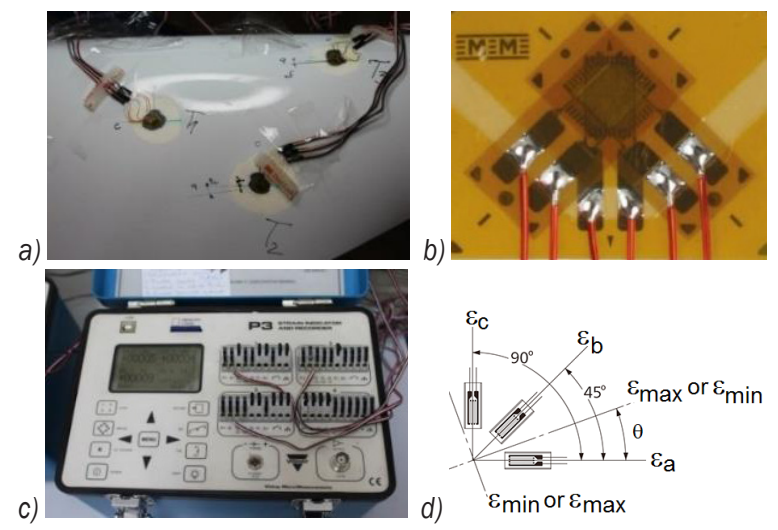

Fig. 6. Strain gauges measurements: a) stress/strain gauge; b) rectangular 3 stacked rosette; c) Vishay P3 strain indicator and recorder; d) positioning of the stacked gauges 
For increased structural strength and stiffness at $0.286 \mathrm{R}(\mathrm{R}$ - the total length of distance between the center of rotor and the tip of blade), the same NACA has been applied both for the upper surface (the top face were sensors are placed) and lower surface (bottom face of the blade), keeping the aerodynamically performances of the blade's tip [15].

The profiles between $0.268 \mathrm{R}$ and tip were linear interpolated. A compromise has to be found between high-resolution and long propagation distance.

Three sensors C2A-06-062WW-350, stacked rosette were used, each having 3 strain gauges with $350 \Omega$ electrical resistance were employed (Figs. 6 $\mathrm{a}$ and $\mathrm{b}$ ). These were connected to Vishay P3 Strain Indicator and recorder (Fig. 6c), in quarter bridge connection with automatic balance.

Their positioning (Fig. 6d) has allowed the determination of deformations due to bending along blade axis at distance of $488 \mathrm{~mm}$ from the fixed end, respectively close to trailing edge at $409 \mathrm{~mm}$ from the fixed end, as well as closely to the leading edge at 351 $\mathrm{mm}$ from the hub. The bending test were effectuated in 7 loading stages with $100 \mathrm{~N}$ steps, with maximum of bending momentum of $900.90 \mathrm{Nm}$.

\section{EXPERIMENTAL RESULTS AND DISCUSSIONS}

The simulation of blade behavior has been carried out with ANSYS Academic 17.2 at $300 \mathrm{~mm}$ distance from the tip of the blade, a compression force of $500 \mathrm{~N}$ has been applied on $\mathrm{Y}$ axis (blade upper shell) on a region with $100 \mathrm{~mm}$ width. The produced displacement of the tip is of $30.082 \mathrm{~mm}$. Fig. 7a presents the division of the blade in critical regions, in Fig. $7 \mathrm{~b}$ is presented the loading forces disposition towards blade axis. The FEM model shown above takes into account the presence of the reinforcement structure, which's mass cannot be neglected, especially if one considers that the distance from the axis of rotation increase the inertia and can reduce the frequency associated with the first mode of vibration of WTB. Fortunately, the glass fibers employed makes the structure very rigid. OF sensors are placed in region at $307 \mathrm{~mm}, 362 \mathrm{~mm}$, $406 \mathrm{~mm}$ from the hub fixing in stand. All the loadings are static and the sensors were placed in region with maximum critical points. For establishing critical regions of WTB using FEM, 1338842 nodes, 832563 elements were employed, the maximum dimension of an element being $8 \mathrm{~mm}$.

The resulted maximum stresses were under material flow limit. In all the cases, the stresses on lower shell are higher than on the upper shell. The maximum stresses on WTB appear closely to the joint between the hub and the longeron and at transition between circular geometry to NACA profile. For the WRS the reader antenna is fixed on the upper part of the stand, at $30 \mathrm{~cm}$ from the middle area of WRS placement locus.

The antenna is connected to a logger reader coupled to a personal computer (PC) by universal serial bus (USB). IC frequency range is $840 \mathrm{MHz}$ to $960 \mathrm{MHz}$. The results of bending tests in a loadingunloading cycle are presented in Figs. $8 \mathrm{a}$ and $\mathrm{b}$. Maximum deformations at $700 \mathrm{~N}$ loadings are characteristics of region where sensor S1 (see inlet in Fig. 5a) is placed (along longeron axis) and the minimums are in the region of sensor S2 (placed outside the critical zone). In addition, the deformation is linear, the loading remain in elastic range. During the unloading, the values follow the same characteristic as at loading.

Comparing loading/unloading data at $500 \mathrm{~N}$ with the simulated ones, it can be observed a good correlation of the displacement, experimentally being determined as $37 \mathrm{~mm}$. The OF sensor, FBG single DTG S-01 type used for monitoring composite materials type GFRP [39] have center wavelength in a)

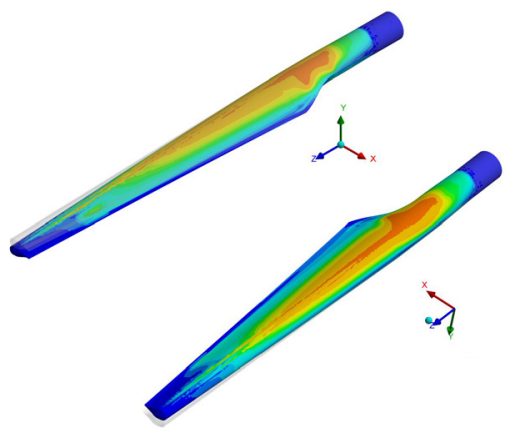

b)

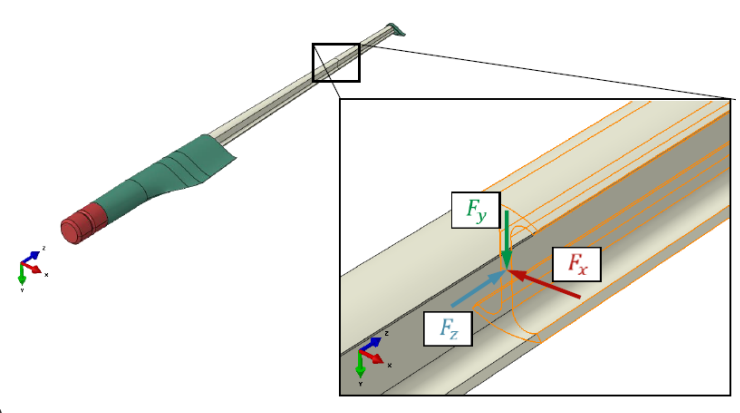

Fig. 7. FEM simulation of WTB: a) division of blade in critical regions; $b$ ) loading forces disposition 
a)

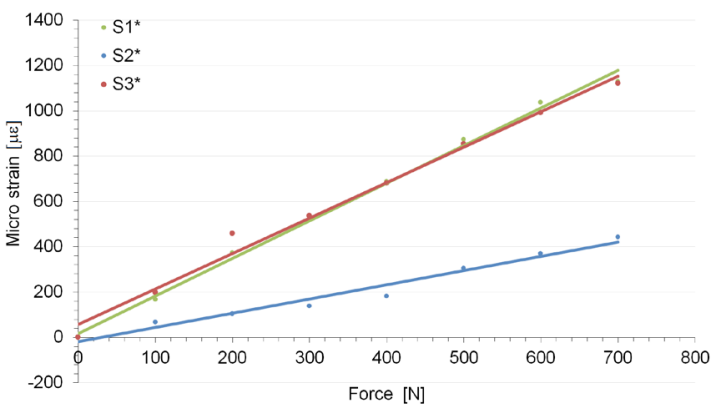

Fig. 8. Signal delivered by the three WRS placed in different critical regions of WTB: a) loading; b) unloading

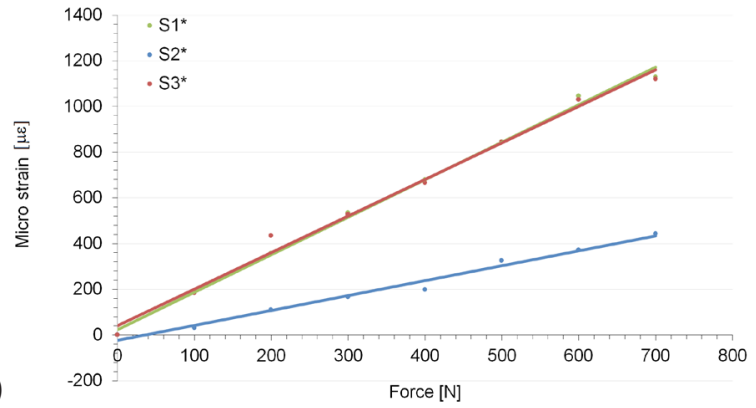

$1535 \mathrm{~nm}$ with strain sensitivity $7.8 \times 10^{-7} \mu \varepsilon^{-1}$ and temperature sensitivity $6.5 \times 10^{-6} \mathrm{~K}^{-1}$.

This is connected at optical system FS22 Industrial BraggMETER HBM Germany coupled with PC. During the experiments, the temperature has been maintained constant at $22 \pm 1{ }^{\circ} \mathrm{C}$. The experimental test setup was performed according to [40], progressively loading/unloaded forces were applied.

Physically, stress concentration around the damage in the composite laminates can be directly observed from row sensor signal. The data processing has been made in Matlab 2014b, the temperature correction being made, the equipment indicating the temperature of fiber, too. Fig. 9a presents the raw data recorded by the device for different loadings. The relative variation of Bragg wavelength was determined in function of loading is presented in Fig. 9b showing that the relative variation of Bragg wavelength is linear. The dependency strain-load for WTB in a loading-unloading cycle for three sets of experimental measurement is presented in Fig 9. The same linear dependency strain-load can be shown, even the existence of a remnant stress at force removal, indicating an accumulation of energy in WTB composite structure, preponderant in the resin.

The measurements using OF were carried on the same time with those using WRS sensors.

The sensor denoted T1 measures the deformations of the blade in the plane of I shape longeron, having height/width variable along the blade, T2 measures the deformations of blade shell closely to the trailing edge and T3 measures the deformations of blade shell closely to leading edge. The experimental data were used to calculate [40] maximum specific deformation $\varepsilon_{\max }$, minimum specific deformations $\varepsilon_{\min }$, acute angle from the axis $\theta$, the maximum shear strain $\gamma_{\max }$, maximum normal stress $\sigma_{\max }$, minimal normal stress $\sigma_{\min }$ and tangential maximum stress $\tau_{\max }$.

Fig. 10 presents the plotting of $\sigma_{\max }, \sigma_{\min }$ and $\tau_{\max }$ for the 3SG for loading (Figs.10 a, c and e) and unloading (Figs. $10 \mathrm{~b}, \mathrm{~d}$ and $\mathrm{f}$ ) until maximum force of $700 \mathrm{~N}$. It can be observed that the high values of stresses with applied force appears in the region where sensor T3 is placed, this region being emphasized in FEM analysis too. The difference between maximum stress of loading and unloading is given due to the static conditions of measurements. The studied
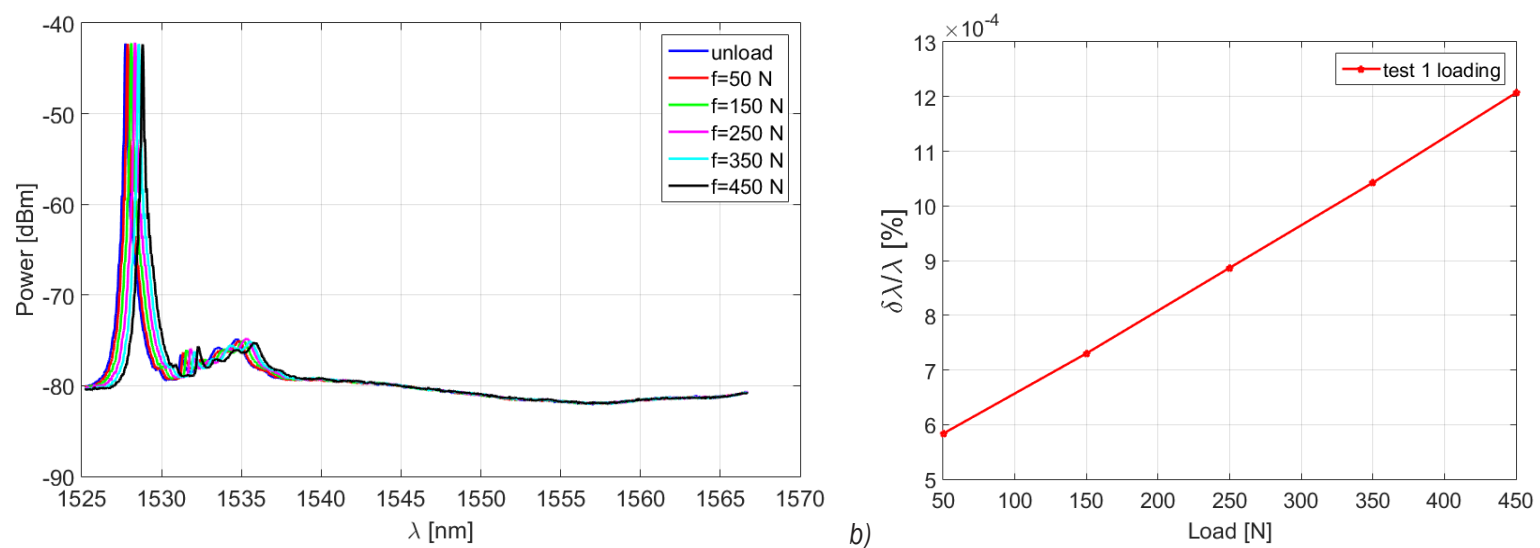

Fig. 9. FBG measurements: a) response to successive loading; b) relative variation of Bragg wavelength 

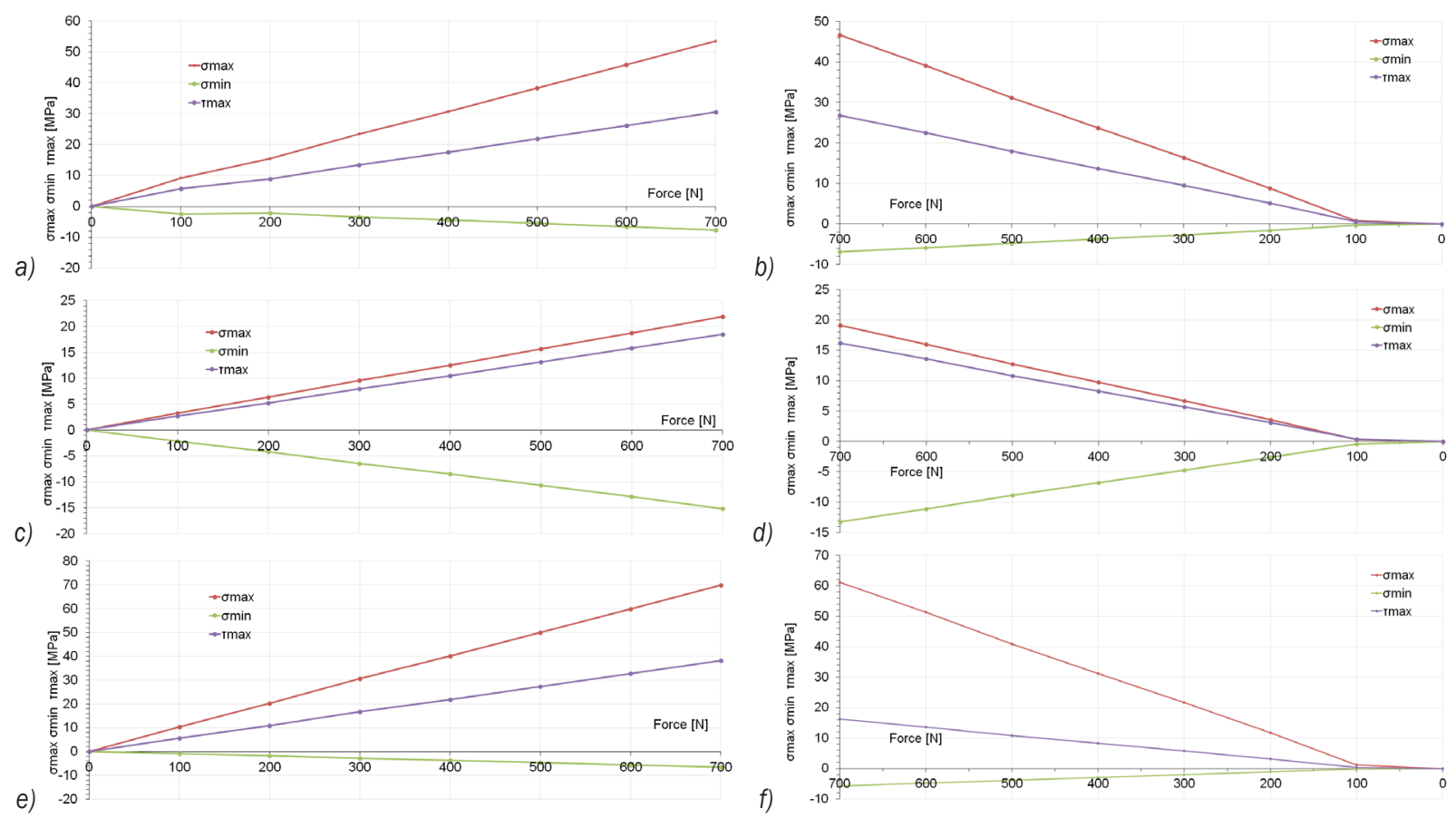

b)

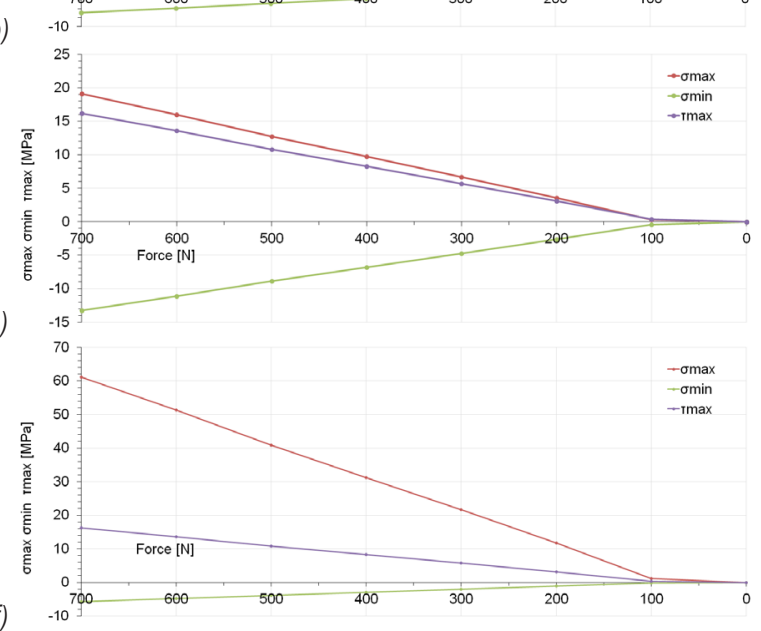

Fig. 10. Variation of stresses with force: a) rosette 1 - loading; b) rosette 1 - unloading;

c) rosette 2 - loading; d) rosette 2 - unloading; e) rosette 3 - loading; f) rosette 3 - unloading

composite materials store the energy. The plots following the same profile shows that the tests were carried out in elastic range.

\section{CONCLUSIONS}

Monitoring of complex structures has become an economic necessity, the trend consisting in using of a lot of sensors (described in this paper, i.e. not only) to detect broken fibers which may occur and develop under moderated loads, or cracks and delamination due to low energy impacts, etc.

Practical applications demonstrates that, in order to avoid environmental disasters, it is necessary to establish diagnosis and prognosis methods, based on using information obtained from sensors constructed on known physical principles.

The monitoring is close related with nondestructive evaluation and the trend is to obtain real time information. Scalable WTB have been constructed and tested to loadings using WRS, OFFBG and SG located in the maximum concentration stress zones.

The tests were carried on scalable models, in the further research the WRS sensors will be embedded, because in the frame of the project that sustains the paper, the blades will be employed into a demonstrator to show the righteous of solutions, reliability of correct diagnosis probability, prognosis, and evaluation of residual lifetime and maintenance management.

\section{ACKNOWLEDGEMENTS}

This paper is partially supported by Romanian Ministry of Research and Innovation under project Nucleus Program PN 2018 and under UEFISCDI Grant PN-III-P1-1.2-PCCDI-2017-0239.

\section{REFERENCES}

[1] Wind Energy Targets for 2020 - 2030 (2015). Wind Europe, from https://windeurope.org/about-wind/reports/windenergy-scenarios-2030, accessed 2018-01-24.

[2] GE Renewable Energy (2018). from http://www.ge-energy. com/products_and_services/products/wind_turbines/ ge_1.5_77_wind_turbine.jsp, accessed on 2018-01-24.

[3] RWEA (2018). from http://rwea.ro/cifre-cheie/, accessed on 2018-01-24.

[4] Xiang, D., Jiang, L., You, M., Shen, Y. (2017). Influence of quasi-steady, wind loads on the fatigue damage of wind turbine gearboxes. Strojniški vestnik - Journal of Mechanical Engineering, vol. 63 , no. 5, p. 300-313, Dol:10.5545/svjme.2016.4224.

[5] Chen, J., Yang, R., Ma, R., Li, J. (2016). Design optimization of wind turbine tower with lattice-tubular hybrid structure using particle swarm algorithm. The Structural Design of Tall and 
Special Buildings, vol. 25, no. 15, p. 743-758, Dol:10.1002/ tal.1281.

[6] Kusiak, A., Song, Z. (2010). Design of wind farm layout for maximum wind energy capture. Renewable Energy, vol. 35, no. 3, p. 685-694, D0l:10.1016/j.renene.2009.08.019.

[7] Kaidis, C., Uzunoglu, B., Amoiralis, F. (2015). Wind turbine reliability estimation for different assemblies and failure severity categories. IET Renewable Power Generation, vol. 9, no. 8, p. 892-899, D0l:10.1049/iet-rpg.2015.0020.

[8] Yang, J., Peng, C., Xiao, J., Zeng, J., Xing, S., Jin, J., Deng, H. (2013). Structural investigation of composite wind turbine blade considering structural collapse in full-scale static tests. Composite Structures, vol. 97, p. 15-29, D0l:10.1016/j. compstruct.2012.10.055.

[9] Hillmer, B., Borstelmann, T., Schaffarczyk, P., Dannenberg, L. (2007). Aerodynamic and structural design of MultiMW wind turbine blades beyond $5 \mathrm{MW}$. Journal of Physics: Conference Series, vol. 75, p. 012002, D0l:10.1088/17426596/75/1/012002.

[10] Cajal, C., Santolaria, J., Samper, D., Garrido, A. (2015). Simulation of laser triangulation sensors scanning for design and evaluation purposes. International Journal of Simulation Modelling, vol. 14, no. 2, p. 250-264, Dol:10.1088/1742. 6596/75/1/012002.

[11] Ding, Y. Zhang, X. (2016). An optimal design method of swept blades for HAWTs. Journal of Renewable and Sustainable Energy, vol. 8, no. 4, p. 043303, D0l:10.1063/1.4961588.

[12] Chehouri, A., Younes, R., llinca, A., Perron, J., (2015). Review of performance optimization techniques applied to wind turbines. Applied Energy, vol. 142, p. 361-388, D0I:10.1016/j. apenergy.2014.12.043.

[13] González-Cruz, C., Jauregui-Correa, J., Herrera-Ruiz, G. (2016). Nonlinear response of cantilever beams due to large geometric deformations: Experimental validation. Strojniški vestnik - Journal of Mechanical Engineering, vol. 62, no. 3, p. 187-196, DOl:10.5545/sv-jme.2015.2964.

[14] Hassanzadeh, A., Naughton, J.W., Kelley, C.L., Maniaci, D.C. (2016). Wind turbine blade design for subscale testing. Journal of Physics: Conference Series, vol. 753, no. 2, p. 022048, DOl:10.1088/1742-6596/753/2/022048.

[15] Lee, H.G., Kang, M.G., Park, J. (2015). Fatigue failure of a composite wind turbine blade at its root end. Composite Structures, vol. 133, p. 878-885, D0I:10.1016/j. compstruct.2015.08.010.

[16] Balageas, D., Fritzen, C.-P., Güemes, A. (eds.). (2010). Structural Health Monitoring, vol. 90, John Wiley \& Sons, New York.

[17] Yin, A., Lu, J., Dai, Z., Li, J., Ouyang, Q. (2016). Isomap and deep belief network-based machine health combined assessment model. Strojniski vestnik - Journal of Mechanical Engineering, vol. 62, no. 12, p. 740-750, D0l:10.5545/sv-jme.2016.3694.

[18] Adams, D., White, J., Rumsey, M., Farrar, C., (2011). Structural health monitoring of wind turbines: method and application to a HAWT. Wind Energy, vol. 14, no. 4, p. 603-623, D0l:10.1002/ we.437.

[19] Lambert, J., Chambers, A.R., Sinclair, I., Spearing, S.M. (2012). $3 \mathrm{D}$ damage characterization and the role of voids in the fatigue of wind turbine blade materials. Composites Science and Technology, vol. 72, no. 2, p. 337-343, Dol:10.1016/j. compscitech.2011.11.023.

[20] Mandell, J.F., Samborsky, D.D. (2012). SNL/MSU/DOE Composite Material Fatigue Database. Sandia National Laboratories, Albuquerque.

[21] Wang, T. (2012). A brief review on wind turbine aerodynamics. Theoretical and Applied Mechanics Letters, vol. 2, no. 6, p. 062001, DOI:10.1063/2.1206201.

[22] Schubel, P.J., Crossley, R.J. (2012). Wind turbine blade design review. Wind Engineering, vol. 36, no. 4, p. 365-388, DOI:10.1260/0309-524X.36.4.365.

[23] Lachenal, X., Daynes, S., Weaver, P.M., (2013). Review of morphing concepts and materials for wind turbine blade applications. Wind Energy, vol. 16, no. 2, p. 283-307, D0l:10.1002/we.531.

[24] Li, D., Ho, S.C.M., Song, G., Ren, L., Li, H. (2015). A review of damage detection methods for wind turbine blades. Smart Materials and Structures, vol. 24, no. 3, p. 033001 , DOl:10.1088/0964-1726/24/3/033001.

[25] Wind turbine accident compilation (2018). from http://www. caithnesswindfarms.co.uk/fullaccidents.pdf, accessed on 2018-02-10.

[26] Grimberg, R., Tian, G.Y., Savin, A., Steigmann, R., Dobrescu, G.S. (2014). Electromagnetic metamaterial sensors for structural health monitoring. Electromagnetic Nondestructive Evaluation (XVII), vol. 39, p. 3-10, D0l:10.3233/978-1-61499407-7-3.

[27] Xu, J., Dong, Y., Li, H. (2014). Research on fatigue damage detection for wind turbine blade based on high-spatialresolution DPP-BOTDA. Sensors and Smart Structures Technologies for Civil, Mechanical and Aerospace Systems, vol. 906130, Dol:10.1117/12.2044840.

[28] Takeda, S.-I., Aoki, Y., Nagao, Y. (2012). Damage monitoring of CFRP stiffened panels under compressive load using FBG sensors. Composite Structures, vol. 94, no. 3, p. 813-819, D0I:10.1016/j.compstruct.2011.02.020.

[29] Kuang, K.S.C., Kenny, R., Whelan, M.P., Cantwell, W.J., Chalker, P.R. (2001). Residual strain measurement and impact response of optical fibre Bragg grating sensors in fibre metal laminates. Smart Materials and Structures, vol. 10, no. 2, 338-346, DOI:10.1088/0964-1726/10/2/321.

[30] López-Higuera, J.M. (ed.) (2002). Handbook of Optical Fibre Sensing Technology. Wiley, New York.

[31] Gouveia, C.A., Baptista, J.M. Jorge, P.A., (2013). Refractometric optical fiber platforms for label free sensing. Current Developments in Optical Fiber Technology, InTech, London, p. 345-373, D0I:10.5772/55376.

[32] Daliri, A., Galehdar, A., Rowe, W.S., Ghorbani, K. John, S. (2012). Utilising microstrip patch antenna strain sensors for structural health monitoring. Journal of Intelligent Material Systems and Structures, vol. 23, no. 2, p. 169-182, DOI:10.1177/1045389X11432655.

[33] Chen, T., Li, S., Sun, H. (2012). Metamaterials application in sensing. Sensors, vol. 12, no. 3, p. 2742-2765, D0l:10.3390/ s120302742.

[34] Pendry, J.B., Holden, A.J., Robbins, D.J., Stewart, W.J. (1999). Magnetism from conductors and enhanced nonlinear phenomena. IEEE Transactions on Microwave 
Theory and Techniques, vol. 47, no. 11, p. 2075-2084, DOl:10.1109/22.798002.

[35] Pendry, J.B., Holden, A.J., Stewart, W.J., Youngs, I. (1996). Extremely low frequency plasmons in metallic mesostructures. Physical Review Letters, vol. 76, no. 25, p. 4773-4776, D0I:10.1103/PhysRevLett.76.4773.

[36] Savin, A., Steigmann, R., Dobrescu, G.S. (2014). Metamaterial sensors for structural health monitoring. Proceedings of the ASME 12th Biennial Conference on Engineering Systems Design and Analysis, p. 25-27, D0l:10.1115/ESDA201420596.
[37] Vishay (2014). Strain gage rosettes: selection, application and data reduction, Tech Note TN-515, from http://www.vishaypg. com/docs/11065/tn-515.pdf, accessed on 2018-01-24.

[38] FS22 Industrial BraggMETER (2017). Static and Dynamic Optical Interrogators, User Manual, HBM Germany Darmstadt.

[39] ASTM D5868 - 01(2014). Standard Test Method for Lap Shear Adhesion for Fiber Reinforced Plastic (FRP) Bonding, ASTM International, West Conshohocken, Dol:10.1520/D586801 14.

[40] Sciammarella, C.A., Sciammarella, F.M., (2012). Strain gage rosettes: selection, application and data reduction. Experimental Mechanics of Solids, John Wiley \& Sons, New York, p. 111-121, D0l:10.1002/9781119994091.ch5. 